\title{
Effect of Bentonite Prehydration Time on the Stability of Lightweight Oil-Well Cement System
}

\author{
Stephen Adjei, Salaheldin Elkatatny $\mathbb{D}^{D}$, and Abdulaziz Al-Majed \\ Department of Petroleum Engineering, College of Petroleum \& Geosciences, King Fahd University of Petroleum \& Minerals, \\ Dhahran 31261, Saudi Arabia \\ Correspondence should be addressed to Salaheldin Elkatatny; elkatatny@kfupm.edu.sa
}

Received 14 March 2021; Revised 12 May 2021; Accepted 31 May 2021; Published 12 June 2021

Academic Editor: Qingquan Liu

Copyright (C) 2021 Stephen Adjei et al. This is an open access article distributed under the Creative Commons Attribution License, which permits unrestricted use, distribution, and reproduction in any medium, provided the original work is properly cited.

\begin{abstract}
Lightweight cement systems are used in the weak intervals of petroleum wells. Sodium bentonite is used as an extender in lightweight oil-well cement systems as it prevents excess water and sedimentation of particles, thereby ensuring the formation of homogenous and stable cement sheaths. The extending ability of sodium bentonite is enhanced when prehydrated. However, the optimum bentonite prehydration time and its effect on the stability of lightweight cement systems have not been well established. The objective of this study is to investigate the optimum sodium bentonite prehydration time and correlate it to the stability of lightweight oil-well cement systems. Bentonite suspensions were prepared by vigorous preshearing at $12000 \mathrm{rpm}$ for 5 minutes, followed by aging times of $0,30,60$, and 120 minutes. The swelling behavior of bentonite was investigated using a laser particle size analyzer. The Herschel-Bulkley model was used to determine the rheological parameters of the experimentally measured shear stress vs. shear rate data of the aged suspensions. The effect of calcium chloride salt on aged bentonite suspensions was investigated. Density measurements and pore space analysis with the nuclear magnetic resonance (NMR) technique were used to investigate the homogeneity of cement-based cores. It was observed that bentonite swells with time and, after 30 minutes, the swelling is insignificant; however, the swelling property did not have any observed impact on the properties of cement systems designed with the bentonite aged at different times. In general, all the lightweight cement slurries exhibited similar properties, in terms of rheology, stability, and homogeneity, regardless of the bentonite prehydration time. These findings indicate that aging bentonite suspension after vigorous preshearing in lightweight cement design is unnecessary and would only contribute to nonproductive time.
\end{abstract}

\section{Introduction}

Bentonite is a clay obtained from volcanic rock [1]. It is a type of smectite clay containing the montmorillonite mineral and certain amounts of quartz, feldspar, cristobalite, pyrite, illite, and mica [2]. The montmorillonite is classified as a 2:1 clay mineral because it is composed of two silicon tetrahedral sheets that share oxygen atoms with an octahedral aluminum sheet placed between them [3-5]. The three-layered montmorillonite clay mineral with initially neutral layers becomes negatively charged through isomorphic substitution which occurs, for instance when aluminum substitutes silicon in a tetrahedron sheet or magnesium substitutes aluminum in an octahedron sheet $[1,6,7]$. Isomorphism is an important phenomenon in bentonite as the mineral gets its unique characteristics when the negatively charged surface is balanced by exchangeable cations $\left(\mathrm{Ca}^{2+}, \mathrm{Na}^{+}\right.$, and $\left.\mathrm{Mg}^{2+}\right)$. If the dominant exchangeable cation in the bentonite is $\mathrm{Na}^{+}$, the resultant clay is known as sodium bentonite and it is calcium bentonite if $\mathrm{Ca}^{2+}$ is exchanged [7-9].

The sodium bentonite is very useful in cement composites because of its ability to swell when dispersed in water and also to form stable dispersions $[7,10]$. As an extender in lightweight cement systems, bentonite acts as a free water controller, fluid loss additive, or antisettling agent [11-13]. 
The bentonite-based cement slurries can be prepared either by dry mixing the clay and the cement or by prehydrating the clay in the mix water before adding the cement [14]. In a cement slurry design, complete hydration of bentonite in the mix-water is beneficial as the $\mathrm{Ca}^{2+}$ ions present in the cement slurry inhibit its hydration $[15,16]$.

As stated by earlier authors, prehydrating the bentonite enhances its extension performance and increases slurry yield [17-19]. For instance, cement slurry containing $8 \%$ BWOC (by weight of cement) dry-mixed bentonite is comparative to another composed of $2 \%$ BWOC prehydrated bentonite [20].

In some operations, the bentonite is presheared for some time, mostly at low and high shear rates for a period, e.g., for 5 minutes, before the addition of the chemical additives and binders. Smith and Okla [21] had suggested that bentonite should only be presheared and argued that aging the bentonite after preshearing had no significant impact on cement properties, observing similar settling behavior irrespective of the bentonite prehydration time. The authors suggested that premixing the bentonite for 20 seconds was enough. They further stated that allowing the bentonite to hydrate for 24 hours increased settling and hence recommended that the bentonite suspension be used without aging. Messenger [22] backed the argument presented by Smith and Okla [21], adding that clay hydration happens during the shearing period, and hence, there is no need to age the suspension. However, some recent studies have disputed the earlier findings. Ramachandran [23] indicated that the minimum length for prehydration (aging) should be 2 to 3 hours, while Nelson and Guillot [19] argued that the bentonite should be prehydrated for approximately 30 minutes.

This is a very important study because if bentonite prehydration time does not have any significant impact on the desirable properties of the bentonite; then, aging bentonite slurries as suggested by others would only add to the nonproductive time (NPT) and increase the cost of well cementing. While no empirical reasons were given in some of the above arguments, other authors made conclusions based on the settling characteristics of cement systems designed with bentonite slurries aged at different times. The objective of this current study is to address this disagreement regarding the optimum bentonite prehydration time. Unlike the earlier studies where the properties of only cement systems were studied, the current authors study the effect of bentonite prehydration time on the colloidal properties of the bentonite powder and subsequently correlate the properties of aged bentonite suspensions (rheology and swelling) to the stability (free water and cement homogeneity) of lightweight cement systems. We include pore space analysis of cement-based cores as a measure of homogeneity using the nuclear magnetic resonance (NMR) technique.

The following section represents the materials used in this study with detailed explanation of the methods used followed by the results and discussion section which represents the main finding of this study with a detailed explanation of it. Finally, we conclude our paper based on the obtained results and we summarized it in the summary and conclusion section.

\section{Materials and Method}

2.1. Materials. Class G cement was chosen for this study because it is commonly used in the field and is compatible with many chemical admixtures. About $90 \%$ of the cement particles have their size to be lower than $58.13 \mu \mathrm{m}$. The mineral phases in the cement are alite (82 wt.\%), belite (17 wt.\%), quartz $(0.1 \mathrm{wt} . \%)$, and dolomite $(0.9 \mathrm{wt} . \%)$. The crystalline phases in the commercial sodium bentonite include montmorillonite (14.9wt.\%), illite (19.3 wt.\%), albite (47.9 wt.\%), heulandite (9.2 wt.\%), cristobalite (4.5 wt.\%), calcite (2.4 wt.\%), and quartz (1.9 wt.\%).

The chemical composition and density of the cement and sodium bentonite are given in Table 1 . The $\mathrm{Na}_{2} \mathrm{O} / \mathrm{CaO}$ of the bentonite is 1.14 , associated with sodium bentonite.

\section{Method}

Bentonite is used in cement paste design in about 2-20\% by weight of cement (BWOC) [23]. Bentonite suspensions were prepared using the powder in concentrations of $4 \%$ BWOC. The clay was sheared at $4000 \mathrm{rpm}$ for 15 secs and then continued at $12000 \mathrm{rpm}$ till the 5-minute set time was up. The suspensions were aged at different times. The slurry aged at zero time; that is, only presheared was labeled PS_0. The same nomenclature was adopted for all the bentonite suspensions, using PS and the aged time (e.g., PS_30 for 30-minute prehydration time).

The swelling behavior of the bentonite at 30,60, 90, and 120 minutes was analyzed using the Mastersizer 2000 laser PSD analyzer by Malvern.

The rheology was measured using the OFITE model 900 viscometer. The aged suspensions were vigorously homogenized and then transferred into the viscometer cup. The bentonite slurries were then stirred at $600 \mathrm{rpm}$ for 75 secs to ensure temperature equilibration before the rheological study was done.

The effect of calcium chloride salt on the bentonite hydration process was also evaluated. About 2\% BWOC $\mathrm{CaCl}_{2}$ was added to the aged bentonite suspensions. The mixture was poured into a $100 \mathrm{ml}$ cylindrical flask and left to stand for 2 hours at room temperature. The volume of the supernatant was recorded.

Approximately $13.5 \mathrm{ppg}\left(1.62 \mathrm{~g} / \mathrm{cm}^{3}\right)$ lightweight cement slurries were prepared with the aged bentonite suspensions. Calcium chloride was used as the accelerator. The effect of the bentonite prehydration time on lightweight cement systems was investigated. The samples were cured at $131^{\circ} \mathrm{F}$ in a water bath for 72 hours. Using the nomenclature adopted for the prehydration (PS_0, PS_30, etc.), the letter "C" was attached in the case of cement systems designed with the aged suspensions (e.g., PS_0C for cement designed without aging the bentonite). The slurry preparation and stability tests were according to [24]. The density of different sections of the hardened cement-based cores was measured using the ULTRAPYC 1200e automatic density analyzer supplied by Quantachrome Instruments. The pore space analysis of the top, middle, and bottom sections of hardened cylindrical cement cores was investigated using the nuclear magnetic 
TABLE 1: Chemical composition of cement and sodium bentonite.

\begin{tabular}{lcccccccccccc}
\hline \multirow{2}{*}{ Material } & \multicolumn{1}{c}{ Chemical oxides (wt.\%) } \\
& $\mathrm{SiO}_{2}$ & $\mathrm{Al}_{2} \mathrm{O}_{3}$ & $\mathrm{Fe}_{2} \mathrm{O}_{3}$ & $\mathrm{CaO}$ & $\mathrm{MnO}$ & $\mathrm{K}_{2} \mathrm{O}$ & $\mathrm{Na}_{2} \mathrm{O}$ & $\mathrm{MgO}$ & $\mathrm{SO}_{3}$ & $\mathrm{TiO}_{2}$ & $\mathrm{SrO}^{2} \mathrm{Density}\left(\mathrm{g} / \mathrm{cm}^{3}\right)$ \\
\hline Cement & 19.53 & 3.25 & 7.29 & 62.12 & 0.00 & 1.30 & 0.00 & 1.05 & 4.66 & 0.00 & 0.00 & 3.20 \\
Sodium bentonite & 62.43 & 15.26 & 9.32 & 0.00 & 5.12 & 1.19 & 5.83 & 0.00 & 0.00 & 0.48 & 0.38 & 2.3 \\
\hline
\end{tabular}

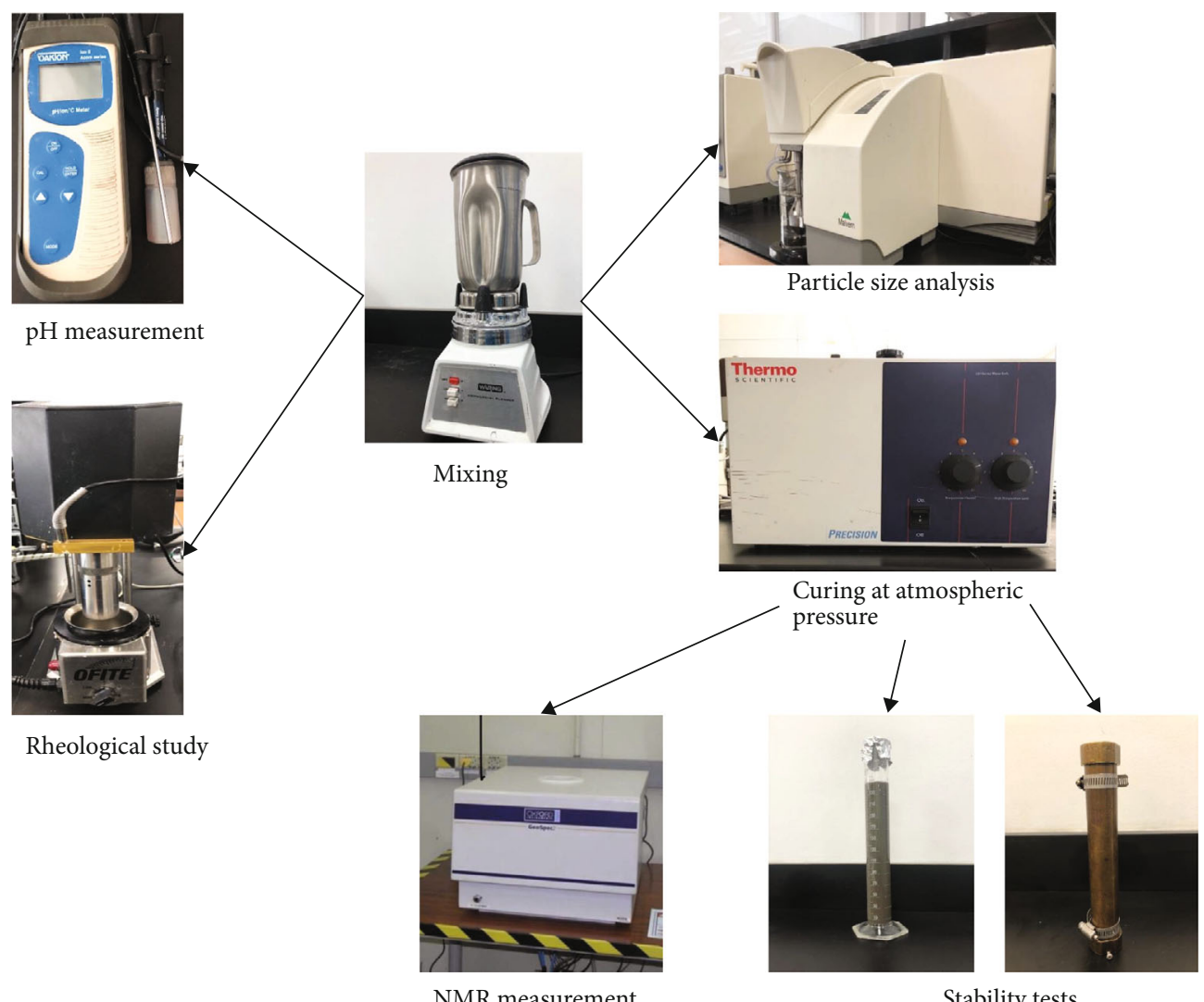

FIgURE 1: Flow chart of experimental work.

resonance (NMR) technique. A flow chart of the experimental work is shown in Figure 1.

\section{Results and Discussion}

4.1. Swelling Behavior of Bentonite Particles. The swelling behavior is very important as it directly affects the macroscopic behavior of bentonite suspensions [6]. The median particle size and $D_{50}$ and $D_{90}$ diameters were used to characterize the particles as they swell with time. Figure 2 shows the swelling behavior of the clay at $0,30,60,90$, and 120 minutes. The particle size increases by $2088.32 \%$ for $D_{50}$ and $196.00 \%$ for $D_{90}$ from time zero to 30 minutes. The variation in particle size after 30 minutes is not significant. This swelling property is due to the material's ability to hold water in its interlayer [7]. The conclusion is that preshearing without aging does not ensure adequate swelling of the bentonite particles. However, more tests would have to be performed to ascertain whether the volume swelled through preshearing only could impact the cement slurry in the same way as that in aged bentonite slurries.

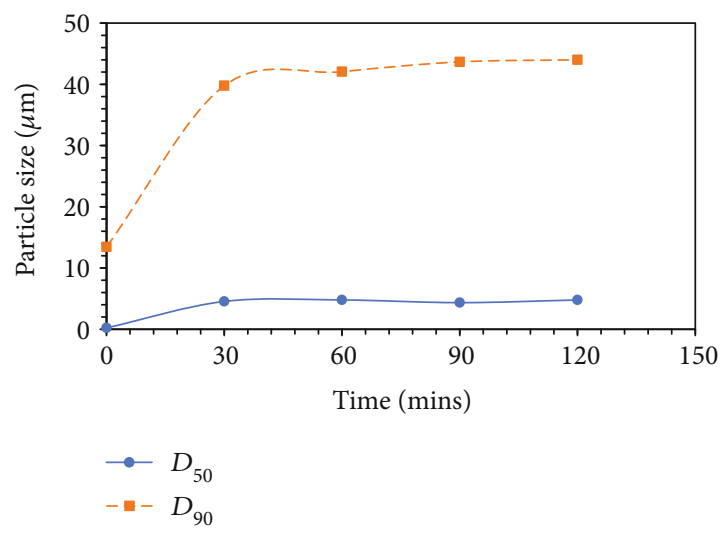

FIgURE 2: Swelling behavior of bentonite particles with age.

4.2. Rheology. Rheological analysis can be used to assess the stability of bentonite-water dispersions; however, this is a complex task as the rheology of bentonite suspension is affected by many factors including temperature, mixing time, 

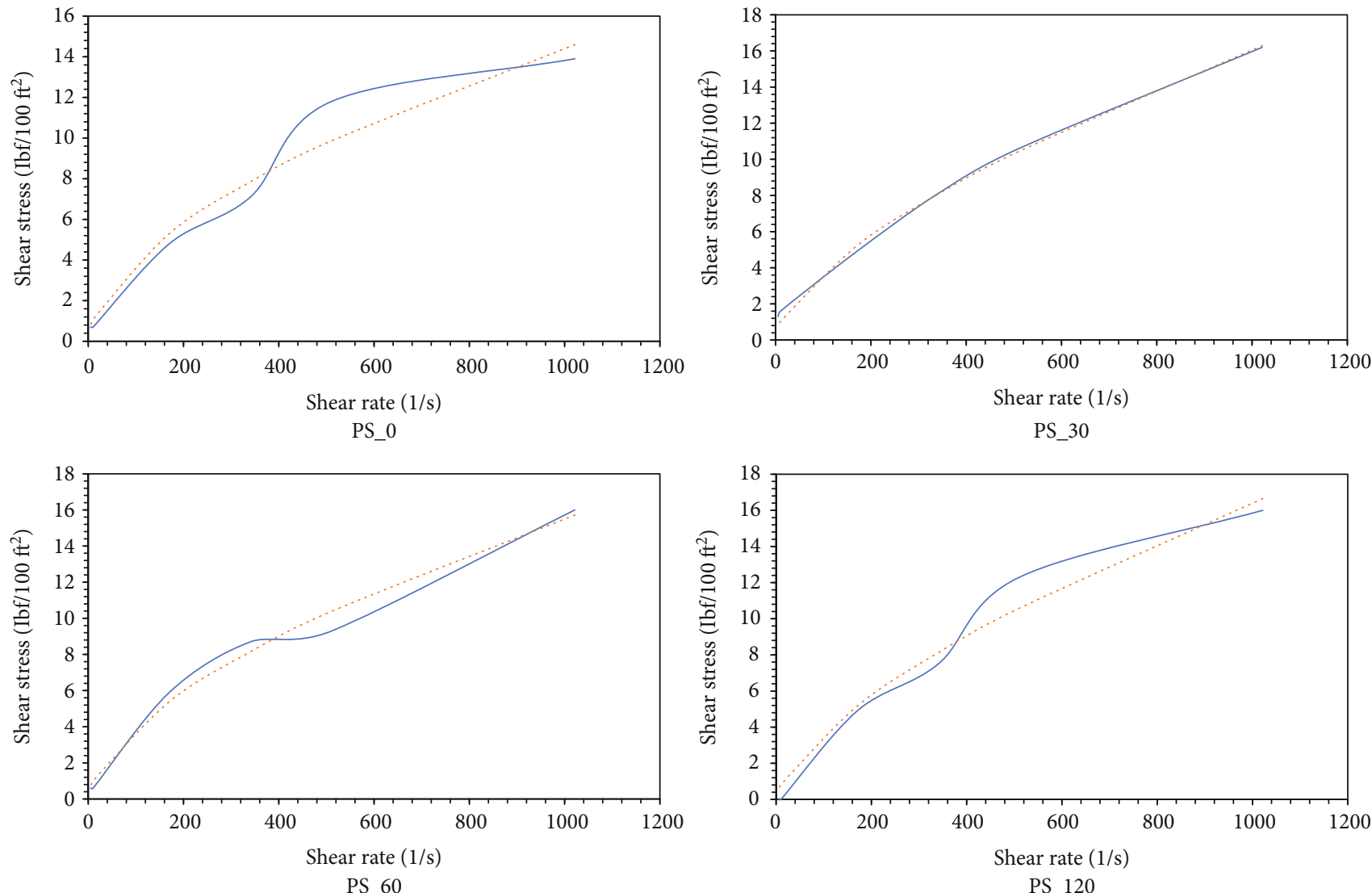

- Experimental data

HB model

FIgURE 3: Shear rate vs. shear stress for experimental data and HB model.

TABLE 2: Rheology of aged bentonite suspensions.

\begin{tabular}{lccc}
\hline $\begin{array}{l}\text { Bentonite } \\
\text { suspensions }\end{array}$ & $\begin{array}{c}\text { Yield stress } \\
\left(\mathrm{lbf} / 100 \mathrm{ft}^{2}\right)\end{array}$ & $\begin{array}{c}\text { Consistency index, } k \\
\left(\mathrm{lbf}-\mathrm{sec}^{\mathrm{n}} / 100 \mathrm{ft}^{2}\right)\end{array}$ & $\begin{array}{c}\text { Flow } \\
\text { behavior } \\
\text { index, } n\end{array}$ \\
\hline PS_0 & 0.00 & 0.29 & 0.56 \\
PS_30 & 0.10 & 0.25 & 0.60 \\
PS_60 & 0.00 & 0.25 & 0.60 \\
PS_120 & 0.00 & 0.18 & 0.65 \\
\hline
\end{tabular}

mixing procedure, $\mathrm{pH}$, electrolyte concentration, particle size, particle size distribution, and shear history $[7,25,26]$.

Conventionally, the materials for the cement slurry design are admixed with the bentonite suspension after preshearing or aging. The state of the bentonite suspension, for instance, its temperature, would affect the properties of the system and hence the cement slurry. The freshly prepared bentonite slurry was observed to be initially warm due to the vigorous shearing at $12000 \mathrm{rpm}$ for 5 minutes, and the aged samples would take some time to reach the room temperature. The PS_0 suspension had an initial temperature of about $90^{\circ} \mathrm{F}$. The rheology for the $30 \mathrm{mins}, 60 \mathrm{mins}$, and 120 mins aged bentonite slurries was measured at their stable temperatures of $82^{\circ} \mathrm{F}, 78^{\circ} \mathrm{F}$, and $74^{\circ} \mathrm{F}$, respectively.

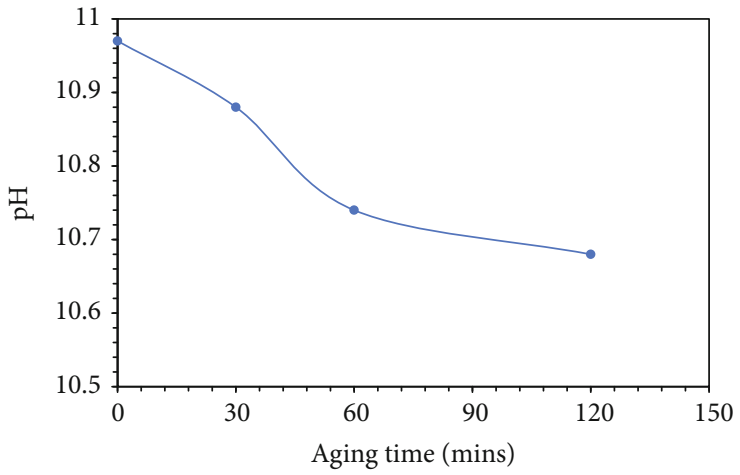

FIgURE 4: The $\mathrm{pH}$ of aged bentonite suspensions.

TABle 3: Effect of $\mathrm{CaCl}_{2}$ on the stability of aged bentonite suspensions.

\begin{tabular}{lc}
\hline Bentonite suspensions & Volume of supernatant $(\mathrm{ml} / 120 \mathrm{mins})$ \\
\hline PS_0_2\% $\mathrm{CaCl}_{2}$ & 0 \\
PS_30_2\% $\mathrm{CaCl}_{2}$ & 0 \\
PS_60_2\% $\mathrm{CaCl}_{2}$ & 0 \\
PS_120_2\% $\mathrm{CaCl}_{2}$ & 0 \\
\hline
\end{tabular}




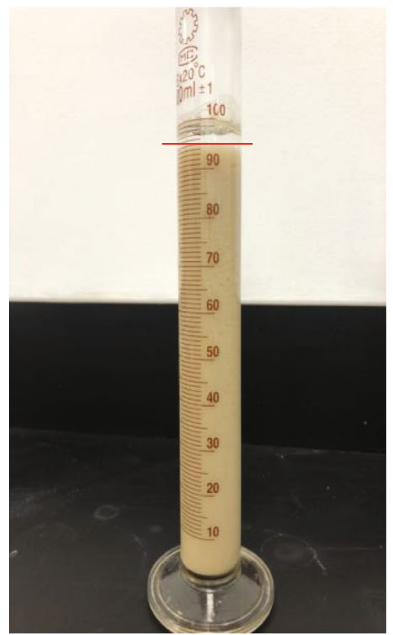

$\mathrm{CaCl}_{2}$ Soln._30 mins

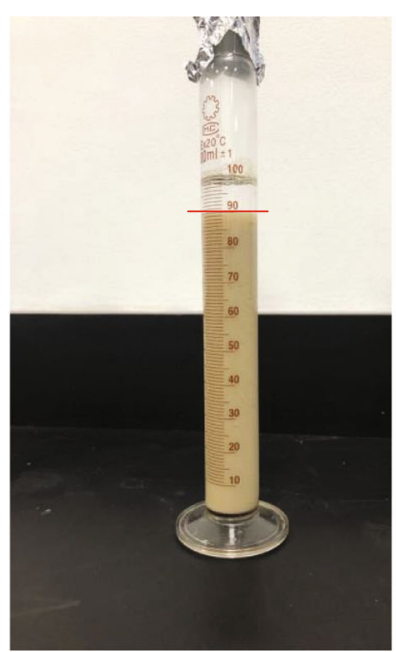

$\mathrm{CaCl}_{2}$ Soln._60 mins

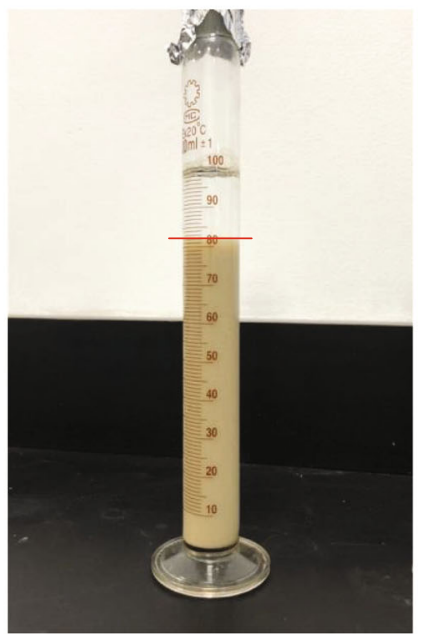

$\mathrm{CaCl}_{2}$ SSoln._120 mins

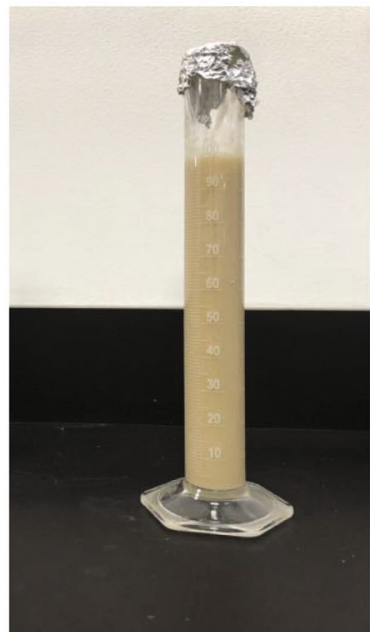

PS_0_2\% $\mathrm{CaCl}_{2-} 120 \mathrm{mins}$

FIgURE 5: Stability of bentonite in $\mathrm{CaCl}_{2}$ solution.

It can be observed in Figure 3 that the consistency curve of the raw data could be closely modeled with the HerschelBulkley (HB) model with a coefficient of determination $\left(R^{2}\right)$ of $0.90-1.0$. The rheology was measured twice, and the results were averaged. The suspensions exhibit pseudoplastic/yield pseudoplastic behavior (shear-thinning), characteristic of bentonite suspensions [25], which arises mostly due to modifications in the structure within the fluid. Table 2 compares the rheological parameters of the bentonite slurries at different ages. It is observed that the consistency index (viscosity) decreases with age, with no difference between the consistency of samples aged for 30 and 60 minutes. All the aged suspensions have a flow index below $1(n<1)$, indicating shear-thinning behavior [27]. The zero (or approximately zero) yield stress for all the suspensions is an indication of a very stable bentonite dispersion, as the yield stress is a measure of the flocculated structure $[25,28]$. These observations may suggest that preshearing without aging was effective, and hence, aging may only increase the nonproductive time (NPT).

4.3. $p H$ of Bentonite Dispersion. Studies have shown that the $\mathrm{pH}$ of sodium bentonite solutions changes with time [6, 29]. The gel structure of bentonite suspension is related to the $\mathrm{pH}$ of the system [7]. The $\mathrm{pH}$ of the suspensions was measured using a $\mathrm{pH}$ meter. The results as indicated in Figure 4 show that the $\mathrm{pH}$ decreases with aging time. The $\mathrm{pH}$ just after preshearing is 10.97 but drops to about 10.68 at 120 minutes. The change in $\mathrm{pH}$ is not very significant, with only a $2.64 \%$ drop in the $\mathrm{pH}$ at the end of 120 minutes, and hence, the temperature and aging time would be the predominant factors controlling the macroscopic behavior.

4.4. Effect of Electrolyte (Calcium Chloride). When the cement slurry is placed behind the casing, it takes several hours before it sets. During this period, the bentonite is expected to maintain its properties and keep the cement composite particles homogeneously dispersed.
Table 4: Free water test.

\begin{tabular}{lc}
\hline Lightweight samples & Volume of free water $(\mathrm{ml} / 250 \mathrm{ml})$ \\
\hline PS_0C & 0 \\
PS_30C & 0 \\
PS_60C & 0 \\
PS_120C & 0 \\
\hline
\end{tabular}

Accelerators are used in lightweight cement design to reduce the thickening time and improve the rate of strength development. $\mathrm{CaCl}_{2}$, an electrolyte, is a commonly used accelerator. When the clay is exposed to water, the sodium ions of the clay mineral and the ions from the bulk medium form the double layer around the particles and generate a repulsive force between them [7]. This force is responsible for the stability of the colloidal system [30]. The addition of calcium ions will suppress the double layer and compromise the network structure, leading to flocculation, sedimentation, and destabilization of the colloidal suspension [7, 29, 31].

$\mathrm{CaCl}_{2}$ is often used in a concentration of $2-4 \%$ BWOC. However, in higher concentrations, the slurry becomes very viscous and would require a dispersant. Preliminary tests showed that $2 \%$ BOWC could be used without requiring a dispersant. The effect of $2 \% \mathrm{CaCl}_{2}$ on the aged bentonite systems prepared with bentonite in a concentration of $4 \%$ BWOC is shown in Table 3. The results indicate that the $\mathrm{CaCl}_{2}$ was unable to weaken the repulsive force between the particles. This would suggest that the vigorous preshearing was able to generate sufficient repulsive force to counteract the compression effect of the calcium chloride.

To explain the above observations, $4 \%$ bentonite powder was added to a $2 \% \mathrm{CaCl}_{2}$ solution $\left(\mathrm{CaCl}_{2-}\right.$ Soln.) instead of adding the $\mathrm{CaCl}_{2}$ to the bentonite suspension. The slurry was left to stand. The slurry was compared to the PS_0_2\% $\mathrm{CaCl}_{2}$ system. Figure 5 compares the state of the slurries. It was observed that the hydration of the bentonite was inhibited in the $\mathrm{CaCl}_{2}$ Soln. system. The clay particles quickly 


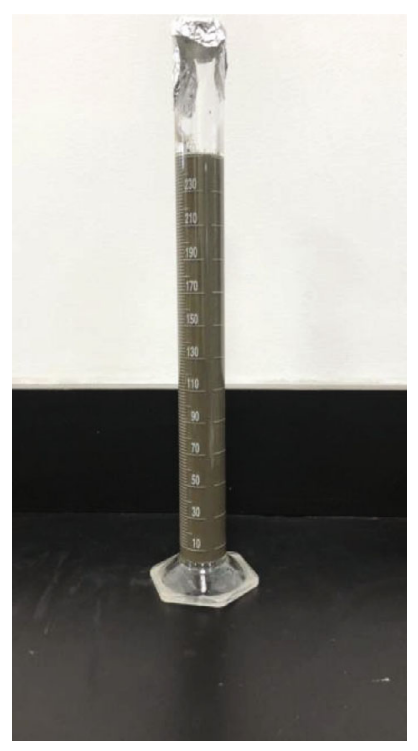

(a) PS_0C

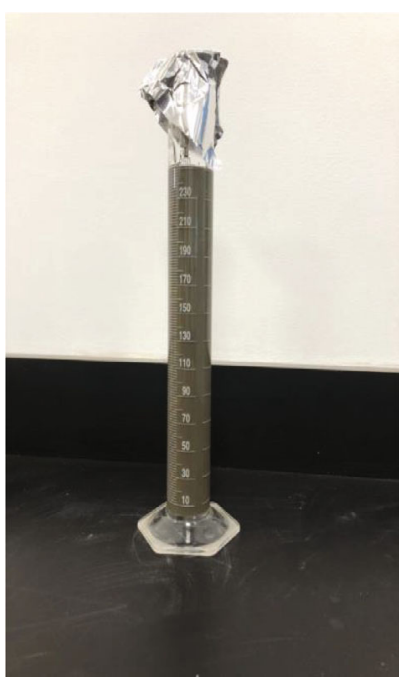

(b) PS_30C

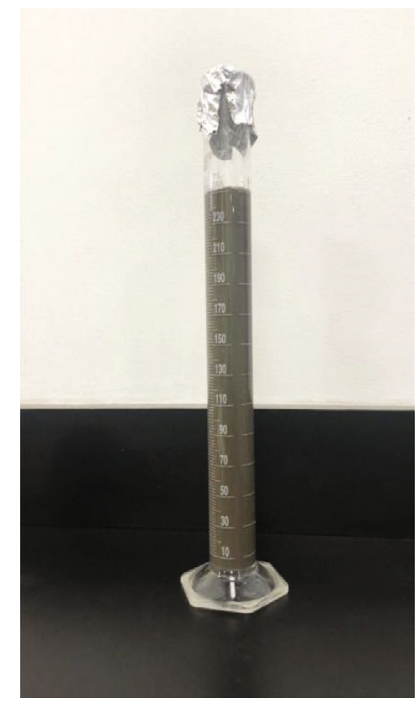

(c) PS_60C

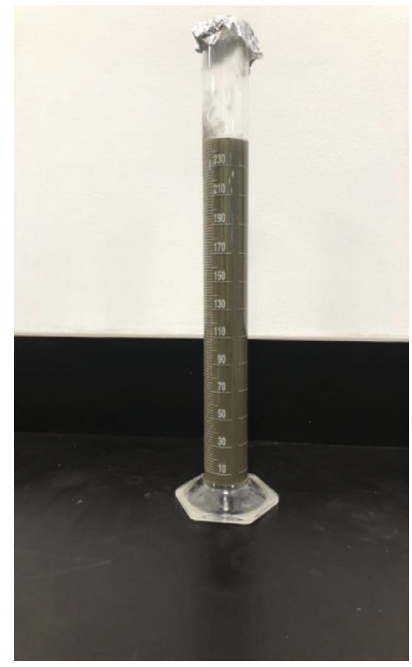

(d) PS_120C

FIgURE 6: State of cement slurries after 2 hours of rest.

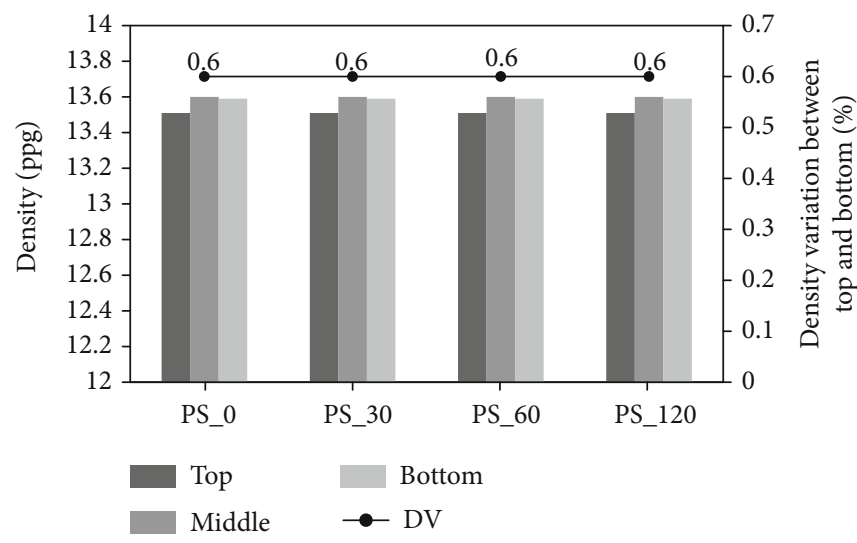

Figure 7: Density variation.

settled with time. The volume of the supernatant at $30 \mathrm{mins}$, $60 \mathrm{mins}$, and $120 \mathrm{mins}$ is $5 \mathrm{ml}, 10 \mathrm{ml}$, and $18 \mathrm{ml}$, respectively. However, compared to the system in which the bentonite was presheared vigorously before the addition of the calcium chloride, the colloidal particles were very stable and the repulsive force between these particles overcame the compression effect of the $\mathrm{Ca}^{2+}$ ions. This indicates that preshearing without aging is sufficient. It also implies that bentonite suspensions should be prepared with deionized water.

\subsection{Stability of Lightweight Cement}

4.5.1. Free Water. Lightweight cement systems, PS_0C, PS_ 30C, PS_60C, and PS_120C, were designed with the PS_0, PS_30, PS_60, and PS_120 bentonite dispersions, respectively.

The results of the free water test are given in Table 4. All the samples have zero free water. It is an indication that the degree of bentonite hydration is independent of prehydration time. This is because the hygroscopic property of bentonite which makes it useful in lightweight cement systems is con- trolled by the exchangeable cations, which was in this case the $\mathrm{Na}^{+}$cation [32]. Visual inspection of the samples in the $250 \mathrm{ml}$ cylinder after the 2-hour test shows homogeneously formed cement pastes, Figure 6 . It must be highlighted that the role of the bentonite is augmented by the calcium chloride which acts as a viscosifier and hence helps inhibit particle sedimentation.

4.5.2. Density Variation. The analysis for the homogeneity of the sample, computed using Equation (1), accounts for the variation in density between the top and bottom sections of cylindrical cement-based cores. The results are shown in Figure 7. As observed, the density variation is the same for all the cement samples, approximately $0.6 \%$ only. This is an indication of highly homogenous cement systems, independent of the prehydration time.

Density variation $(\mathrm{DV} \%)=\left(\frac{\text { bottom density }- \text { top density }}{\text { bottom density }}\right) \times 100$. 

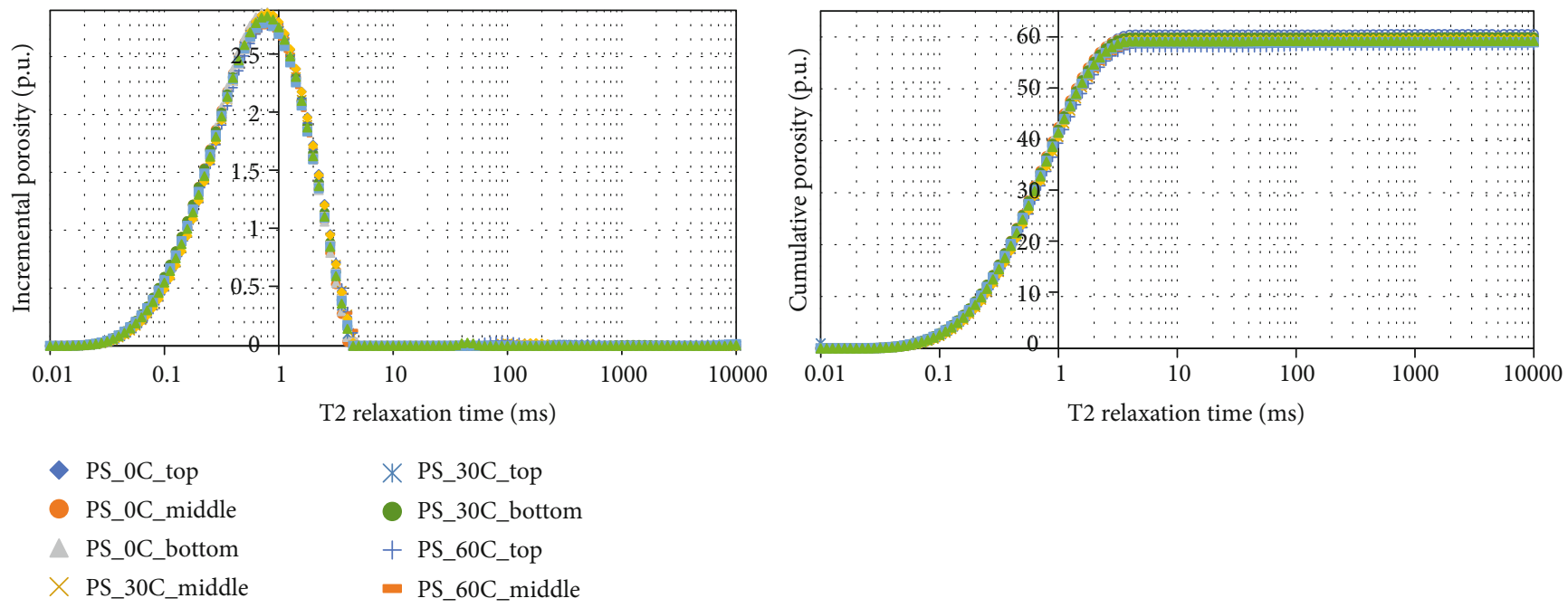

Figure 8: Pore space analysis.

4.5.3. Pore Space Analysis. The NMR analysis was done with the GeoSpec2 Rock Analyzer by Oxford Industries. The transverse relaxation measurement $\left(T_{2}\right)$ was performed on samples saturated with deionized water. The key advantage of the NMR technique for pore space analysis is the ability to capture very small pores [33]. The probability density function curve (PDF): bell shape, and the corresponding cumulative distribution function curve (CDF): $S$ shape, of the pore space of three different sections of cylindrical cement-based cores are shown in Figure 8. Such study can be used to determine the degree of sedimentation and hence the homogeneity and stability of the cement systems. The overlap in both the PDF and CDF curves is an indication of homogeneous pore space for all the systems investigated. The total porosity of all the systems is approximately 0.6 ; such high porosity is associated with water-extended lightweight cement systems. Slight variations in the results would be due to errors that may arise through sample preparation and approximations in measurements before NMR analysis.

The prevention of particle settling and the elimination of free water due to the hydration, swelling, and rheological properties of sodium bentonite leads to the formation of homogeneous cement sheaths. The NMR investigation confirms the findings in the previous tests, suggesting that it is unnecessary to age bentonite slurries, and the vigorous preshearing is adequate to achieve the desired impact of the sodium bentonite.

\section{Summary and Conclusions}

It is preferred to prehydrate sodium bentonite before using it in a lightweight cement system. This activity enhances the extending property of the clay. However, there is a debate concerning the optimum bentonite prehydration time. This study sought to address this confusion. The rheology and stability of aged bentonite suspensions were investigated. The effect of calcium chloride, a commonly used accelerator, on the colloidal property of bentonite particles was also studied. The variation in density and pore space analysis of different sections of cylindrical cement-based cores were used to evaluate the homogeneity of hardened $13.5 \mathrm{ppg}$ lightweight cement pastes. The following observations were made:

(1) Bentonite particles do not fully swell upon preshearing and would require more time to be saturated; however, the swelling achieved with preshearing only was enough to achieve the desired impact of the clay

(2) The vigorous preshearing of bentonite particles at high shear rates for preferably 5 minutes is sufficient, and keeping the suspensions for longer periods would only contribute to nonproductive time

(3) Calcium chloride salt inhibits bentonite hydration, and hence, cement slurries should be designed with deionized water

(4) All the lightweight cement systems designed with bentonite suspensions aged from 0 to 120 minutes exhibited the same homogeneity and stability, characterized by negligible density variation and pore size distribution of the different sections of cured cementbased cores

There is no limitation observed in this study except the test conditions that were applied to the formed slurry besides the concentrations used for each material.

\section{Data Availability}

All the data available in the manuscript.

\section{Conflicts of Interest}

The authors declare no conflicts of interest.

\section{Acknowledgments}

The authors wish to acknowledge King Fahd University of Petroleum \& Minerals for permitting to publish this work. 


\section{References}

[1] F. Bergaya, B. K. G. Theng, and G. Lagaly, Handbook of Clay Science, Developments in Clay Science, 2006.

[2] S. Praetorius and B. Schößer, Bentonite Handbook; Lubrication for Pipe Jacking, Ernst \& Sohn, 2017.

[3] H. V. Olphen, An Introduction to Clay Colloid Chemistry, for Clay Technologists, Geologists, and Soil Scientists, Wiley, 1963.

[4] M. Segad, B. Jönsson, T. Åkesson, and B. Cabane, "Ca/Na montmorillonite: structure, forces and swelling properties," Langmuir, vol. 26, no. 8, pp. 5782-5790, 2010.

[5] F. Uddin, Montmorillonite: An Introduction to Properties and Utilization, in: Current Topics in the Utilization, InTech Open, 2018.

[6] S. Laribi, J. M. Fleureau, J. L. Grossiord, and N. Kbir-Ariguib, "Effect of $\mathrm{pH}$ on the rheological behavior of pure and interstratified smectite clays," Clays and Clay Minerals, vol. 54, no. 1, pp. 29-37, 2006.

[7] P. F. Luckham and S. Rossi, "The colloidal and rheological properties of bentonite suspensions," Advances in Colloid and Interface Science, vol. 82, no. 1-3, pp. 43-92, 1999.

[8] M. H. Baik and S. Y. Lee, "Colloidal stability of bentonite clay considering surface charge properties as a function of $\mathrm{pH}$ and ionic strength," Journal of Industrial and Engineering Chemistry, vol. 16, no. 5, pp. 837-841, 2010.

[9] M. H. Gleason, D. E. Daniel, and G. R. Eykhole, "Calcium and sodium bentonite for hydraulic containment applications," Journal of Geotechnical and Geoenvironmental Engineering, vol. 123, no. 5, pp. 438-445, 1997.

[10] A. Q. Flores, Physical and Mechanical Behaviour of a Two Component Cement-Based Grout for Mechanized Tunneling Application, United Nations University, UNU Geothermal Training Programme, 2019.

[11] W. H. Grant, J. M. Rutiedge, and C. A. Gardner, "Quality of bentonite and its effect on cement-slurry performance," SPE Production Engineering, vol. 5, no. 4, pp. 411-414, 1990.

[12] M. Mousa and M. Alkhamis, New Wellbore-Integrity Classification for Gas Migration Problems and New Cement Formulations Using Graphene Nano Platelets to Prevent Gas Migration through Cement, Missouri University of Science and Technology, 2018.

[13] D. J. Shawn, Introduction to Colloid and Surface Chemistry, Fourth. ed, Elsevier Science Ltd, 1992.

[14] M. A. Fam and J. C. Santamarina, "Study of clay-cement slurries with mechanical and electromagnetic waves," Journal of Geotechnical Engineering, vol. 122, no. 5, pp. 365-373, 1996.

[15] A. S. Al-Yami, "An overview of different chemicals used in designing cement slurries for oil and gas Wells," in SPE Kuwait Oil and Gas Show and Conference, Mishref, Kuwait, October 2015.

[16] P. Hewlett and M. Liska, Lea's Chemistry of Cement and Concrete, Fifth. ed, Elsevier, 2019.

[17] E. Broni-Bediako, "Oil well cement additives: a review of the common types," Oil \& Gas Research, vol. 2, no. 2, pp. 1-7, 2016.

[18] L. M. Murungi, A Review of Casing Cementing Practice for Geothermal Wells in Menengai Field, Kenya, United Nations University, UNU Geothermal Training Programme, 2017.

[19] E. B. Nelson and D. Guillot, Well Cementing. Second Edition, Schlumberger, 2006.
[20] H. F. W. Taylor, Cement Chemistry, Second. ed, Thomas Telford, 1997.

[21] D. K. Smith and D. Okla, Well Cementing Method, p. 3227213, 1966.

[22] J. U. Messenger, "Well cementing process using presheared water swellable clays," US Patent 4,202,413, 1980.

[23] V.S. Ramachandran, Concrete Admixtures Handbook: Properties, Science and Technology. Second Edition, William Andrew, 1996.

[24] API RP 10B-2, Recommended Practice for Testing Well Cements, American Petroleum Institute (API), 2nd edition, 2013.

[25] V. C. Kelessidis, "Yield stress of bentonite dispersions," Rheology, vol. 1, pp. 1-12, 2017.

[26] S. Laribi, J. M. Fleureau, J. L. Grossiord, and N. Kbir-Ariguib, "Comparative yield stress determination for pure and interstratified Smectite clays," Rheologica Acta, vol. 44, no. 3, pp. 262-269, 2005.

[27] K. Y. Choo and K. Bai, "Effects of bentonite concentration and solution $\mathrm{pH}$ on the rheological properties and long-term stabilities of bentonite suspensions," Applied Clay Science, vol. 108, pp. 182-190, 2015.

[28] R. Goh, Y. K. Leong, and B. Lehane, "Bentonite slurries-zeta potential, yield stress, adsorbed additive and time-dependent behaviour," Rheologica Acta, vol. 50, no. 1, pp. 29-38, 2011.

[29] O. Duman and S. Tunç, "Electrokinetic and rheological properties of Na-bentonite in some electrolyte solutions," Microporous and Mesoporous Materials, vol. 117, no. 1-2, pp. 331-338, 2009.

[30] H. Seher, H. Geckeis, T. Fanghänel, and T. Schäfer, "Bentonite nanoparticle stability and the effect of fulvic acids: experiments and modelling," Colloids and Interfaces, vol. 4, no. 2, p. 16, 2020.

[31] V. C. Kelessidis, C. Tsamantaki, and P. Dalamarinis, "Effect of $\mathrm{pH}$ and electrolyte on the rheology of aqueous Wyoming bentonite dispersions," Applied Clay Science, vol. 38, no. 1-2, pp. 86-96, 2007.

[32] H. Liu, B. Xie, and Y. L. Qin, "Effect of bentonite on the pelleting properties of iron concentrate," Journal of Chemistry, vol. 2017, 6 pages, 2017.

[33] M. C. Bowers, R. Ehrlich, J. J. Howard, and W. E. Kenyon, "Determination of porosity types from NMR data and their relationship to porosity types derived from thin section," Journal of Petroleum Science and Engineering, vol. 13, no. 1, pp. 114, 1995. 